\title{
Dispersive micro solid-phase extraction using multiwalled carbon nanotubes combined with portable total-reflection X-ray fluorescence spectrometry for the determination of trace amounts of $\mathrm{Pb}$ and $\mathrm{Cd}$ in water samples
}

\begin{abstract}
Karina Kocot, ${ }^{\mathrm{a}}$ Beata Zawisza, ${ }^{\mathrm{a}}$ Eva Marguí, ${ }^{\mathrm{b}}$ Ignasi Queralt, ${ }^{\mathrm{c}}$ Manuela Hidalgo ${ }^{\mathrm{b}}$ and Rafal Sitko*a

In this paper the combination of dispersive micro solid-phase extraction (DMSPE), using multiwalled carbon nanotubes (MWCNTs) as solid sorbents, with total-reflection X-ray fluorescence spectrometry (TXRF) is proposed for preconcentration and determination of lead and cadmium ions in water samples. The proposed sample preparation is quite simple and economic. After the sorption processes of the metals on the MWCNTs, the aqueous sample is separated by centrifugation and the metal loaded MWCNTs are suspended using a small volume of an internal standard solution and analyzed directly by TXRF. Parameters affecting the extraction process (complexing agent, $\mathrm{pH}$ of the aqueous sample, amount of MWCNTs) and TXRF analysis (volume of the deposited suspension on the reflector, drying mode, and instrumental parameters) have been carefully evaluated to test the real capability of the developed methodology for the determination of $\mathrm{Cd}$ and $\mathrm{Pb}$ at trace levels. For both elements the linear range is observed up to $50 \mathrm{ng} \mathrm{mL} \mathrm{m}^{-1}$. Under optimized conditions detection limits are $1.0 \mathrm{ng} \mathrm{mL}^{-1}$ and $2.1 \mathrm{ng}$ $\mathrm{mL}^{-1}$ for $\mathrm{Cd}(॥)$ and $\mathrm{Pb}(॥)$ ions, respectively. Both of the examined elements can be determined with quantitative recoveries (ca. 100\%) and with an adequate precision (RSD $=6.0 \%$ and $10.5 \%$ for $\mathrm{Cd}(\mathrm{N})$ and $\mathrm{Pb}($ II), respectively). Our results give insight into the possibilities of the combination of DMSPE and TXRF for trace metal determination in different types of environmental waters (sea, river and waste water).
\end{abstract}

Received 9th February 2013

Accepted 13th March 2013

DOI: $10.1039 / c 3 j a 50047 k$

www.rsc.org/jaas observed. ${ }^{1}$ The objectives of green analytical methods are replacing toxic reagents, minimizing waste in laboratory and in consequence miniaturization of classical methods. Because of these trends, liquid-phase microextraction (LPME) and solidphase microextraction (SPME) have become the most valuable alternative techniques to classical LLE and SPE. ${ }^{2}$

SPE has been extensively used for the preconcentration of metals in environmental waters..$^{3-5}$ In general, SPE is a surface dependent process since its kinetics depends directly on the contact surface between the analytes and the solid sorbent. This issue becomes critical when the amount of solid sorbent is reduced to the microscale. In this context, dispersive-based procedures have gained importance as rapid and efficient sample treatment methodologies. ${ }^{6}$ In dispersive solid phase extraction (DSPE) and in dispersive micro solid-phase extraction (DMSPE) the solid sorbent in the $\mu \mathrm{g}$ or $\mathrm{mg}$ range is dispersed in the analyzed solution. Such a strategy promotes the immediate interaction between the analytes and sorbent and shortens the time of sample preparation. After adsorption the analytes held in the solid sorbent are eluted, ${ }^{7-9}$ thermally desorbed ${ }^{\mathbf{1 0}}$ or directly

determined by a suitable spectroscopic technique. ${ }^{11-14}$

\footnotetext{
anstitute of Chemistry, University of Silesia, Szkolna 9, 40-006 Katowice, Poland. E-mail: rafal.sitko@us.edu.pl; Fax: +48 32 2599978; Tel: +48 323591556

${ }^{b}$ Department of Chemistry, University of Girona, Campus Montilivi s/n, 17170-Girona, Spain

“Institute of Earth Sciences “Jaume Almera”, CSIC. Solé Sabarís s/n, o8028 Barcelona, Spain
} 
The nature and properties of the solid sorbent are of prime importance in DMSPE. In practice, the main requirements for a solid sorbent are: (a) the fast and quantitative sorption and elution, (b) a high surface area and high capacity, and (c) high dispersibility in liquid samples. In this context, nanoparticles (NPs) seem to be perfect for use in DMSPE. In general, NPs can be divided into two general groups according to their chemical nature: carbon-based, such as fullerene, carbon nanotubes (CNTs) and graphene, and inorganic NPs including magnetic NPs. ${ }^{15,16}$ Such NPs can be applied in organic ${ }^{7,8,17}$ and inorganic ${ }^{18}$ analyses.

In previous studies we used multiwalled carbon nanotubes (MWCNTs) as solid sorbents in DMSPE procedures for the determination of heavy metal ions ${ }^{\mathbf{1 2 - 1 4}}$ by X-ray fluorescence spectrometry (XRF). Using this technique, the direct quantification of metal species held in solid materials is possible and therefore after the sorption process the loaded MWCNTs with metals were collected onto a filter and analyzed directly by XRF without the need for an additional elution step. In this paper, the combination of DMSPE using CNTs with total-reflection $\mathrm{X}$-ray fluorescence spectrometry (TXRF) for the determination of $\mathrm{Cd}(\mathrm{II})$ and $\mathrm{Pb}$ (II) is proposed. TXRF is a well established analytical technique for multi-element determination in various sample types, especially liquids and powdered or microsamples. ${ }^{19}$ To perform analysis under total-reflection conditions, samples must be provided as thin films. For liquid samples, this is done by depositing $5-50 \mu \mathrm{L}$ of the sample on a reflective carrier and subsequently drying the drop. The TXRF system makes use of the fact that at very low glancing angles of the primary X-ray beam $\left(\sim 0.1^{\circ}\right)$ the primary beam is totally reflected. Therefore, the high background that would generally occur due to scattering from the sample support is absent leading to improved detection limits compared to conventional XRF systems. ${ }^{20}$ Taking into account the micro-analytical capability of TXRF and the possibility to analyze suspensions, the use of MWCNTs as solid sorbents is presented for the first time as an interesting preconcentration strategy to be combined with TXRF spectrometry. Moreover, the very small particle size of MWCNTs made these solid sorbents appropriate to prepare a representative suspension to be analyzed by TXRF, thus avoiding the extraction step. Parameters affecting the extraction process by DMSPE (complexing agent, $\mathrm{pH}$ of the aqueous sample, amount of MWCNTs) and TXRF analysis (volume of the deposited suspension on the reflector, drying mode, and instrumental parameters) have been carefully evaluated to test the real capability of the developed DMSPE + TXRF methodology for the determination of low levels of $\mathrm{Cd}$ (II) and $\mathrm{Pb}$ (II) ions in water samples.

\section{Experimental}

\section{Reagents, materials and solutions}

Stock solutions of $1000 \mathrm{mg} \mathrm{L}^{-1}$ of $\mathrm{Cd}(\mathrm{II}), \mathrm{Pb}(\mathrm{II})$ and Y used for preparation of standard solutions and spiked samples were purchased from Teknolab (Drobak, Norway). All aqueous solutions were prepared using high-purity water obtained from a Milli-Q purifier system (Millipore Corp., Bedford, MA). The
Table 1 Instrumental parameters and measurement conditions

S2 PICOFOX TXRF benchtop spectrometer

Tungsten target X-ray tube

Rating: $50 \mathrm{kV}, 1 \mathrm{~mA}$ (maximum power $50 \mathrm{~W}$ )

Optics: multilayer $\mathrm{Ni} / \mathrm{C}, 17.5 \mathrm{keV}, 80 \%$ reflectivity

Detector: Si drift detector, $10 \mathrm{~mm}^{2},<160 \mathrm{eV}$ resolution $\mathrm{Mn}-\mathrm{K}_{\alpha}$

Working environment: air

Sample station: cassette changer for 25 samples

Measurement time: $2000 \mathrm{~s}$

complexing agent, ammonium pyrrolidine dithiocarbamate (APDC, >99\%) was purchased from Sigma-Aldrich (Madrid, Spain). Concentrated nitric acid (65\%, Suprapur) and ammonium hydroxide (25\%, Suprapur) used to prepare solutions of which $\mathrm{pH}$ was adjusted were purchased from Merck (Darmstadt, Germany). MWCNTs with diameters of 6-9 $\mathrm{nm}$ and lengths of $c a$. $5 \mathrm{~mm}$ were purchased from Sigma-Aldrich (Steinheim, Germany). The procedure used in this paper for the oxidation of the MWCNTs is described in detail in ref. 13. In this work quartz glass discs with a diameter of $30 \mathrm{~mm}$ and a thickness of $3 \mathrm{~mm} \pm 0.1 \mathrm{~mm}$ were used as sample holders for introducing the sample into the TXRF instrument.

To test the real capability of the combination of DMSPE and TXRF spectrometry for the determination of $\mathrm{Pb}(\mathrm{II})$ and $\mathrm{Cd}(\mathrm{II})$, the developed procedure was applied to the analysis of different types of environmental waters including sea, river and waste water samples. All of the analyzed samples were filtered through Millipore filters $(0.45 \mu \mathrm{m})$ and preserved by the addition of an appropriate volume of nitric acid and stored at $4{ }^{\circ} \mathrm{C}$.

\section{Instrumentation and operating conditions}

TXRF analysis was performed using a benchtop spectrometer S2 PICOFOX $^{\mathrm{TM}}$ (Bruker AXS Microanalysis GmbH, Berlin, Germany). The spectrometer specifications and operating conditions used are summarized in Table 1. This instrument is equipped with a tungsten target X-ray tube that allows performing TXRF analysis using K-lines of high atomic number elements such as Cd. An additional advantage of this spectrometer compared to other existing systems is that it uses an air-cooled low-power X-ray tube and a Peltier cooled silicon drift detector and thus, no cooling media and gas consumption are required.

The evaluation of TXRF spectra and calculation of net peak areas of the analytes were performed using the software (Spectra Plus 5.3, Bruker AXS Microanalysis GmbH, Berlin, Germany) linked to the equipment. ${ }^{21}$ For the quantification in TXRF analysis, the software applies a deconvolution routine which uses measured mono-element profiles for the evaluation of peak areas.

\section{Preconcentration procedure and TXRF analysis}

The developed DMSPE procedure was as follows: an aliquot of $20 \mathrm{~mL}$ of sample was placed in a $25 \mathrm{~mL}$ polypropylene plastic conical centrifuge tube. Then, $100 \mu \mathrm{L}$ of $4 \mathrm{mg} \mathrm{mL}^{-1}$ APDC and $100 \mu \mathrm{L}$ of $2 \mathrm{mg} \mathrm{mL}^{-1}$ oxidized-MWCNT suspension were added. 


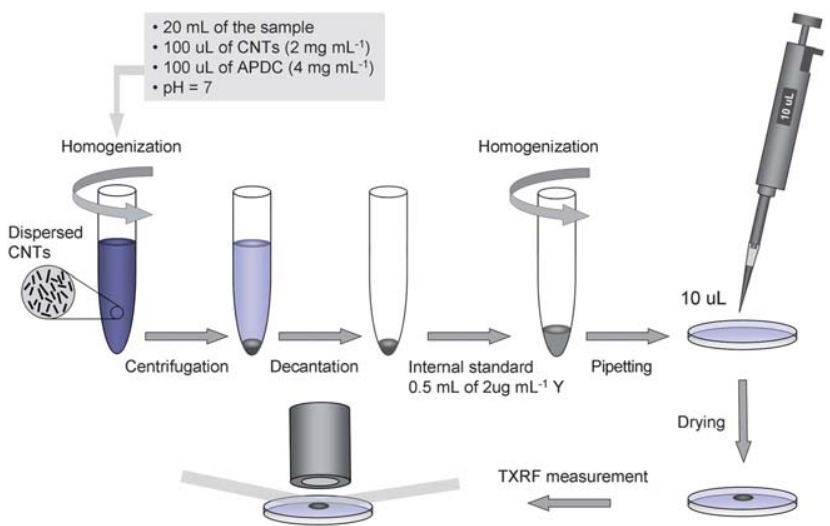

Fig. 1 Schematic setup for the DMSPE procedure combined with TXRF analysis.

The $\mathrm{pH}$ of the sample was adjusted to 7 using $0.1 \mathrm{~mol} \mathrm{~L}^{-1} \mathrm{HNO}_{3}$ and $0.1 \mathrm{~mol} \mathrm{~L}^{-1} \mathrm{NH}_{3}$. Subsequently, the solution was shaken for 5 min. Homogenization was immediately achieved, which promoted the interaction between the Cd(II)-APDC, Pb(II)-APDC complexes and oxidized-MWCNTs. The mixture was centrifuged for $20 \mathrm{~min}$ at $4000 \mathrm{rpm}$. After this process, the dispersed MWCNTs with adsorbed complexes were sedimented at the bottom of the test tube. The clear liquid was then poured off carefully. Then, $500 \mu \mathrm{L}$ of $2 \mu \mathrm{g} \mathrm{mL}{ }^{-1} \mathrm{Y}$ in $2 \mathrm{~mol} \mathrm{~L}^{-1} \mathrm{HNO}_{3}$ (internal standard) was added to the sedimented phase. After homogenization using a Vortex device an aliquot of $10 \mu \mathrm{L}$ was transferred onto a siliconized quartz glass sample carrier and dried under an IR heater for subsequent TXRF analysis (Fig. 1).

\section{Results and discussion}

\section{Evaluation of $\mathrm{Pb}$ and $\mathrm{Cd}$ extraction by DMSPE}

In order to obtain high cadmium and lead preconcentration rates, the effect of different parameters affecting cadmium and lead extraction such as aqueous sample $\mathrm{pH}$, aqueous sample volume, amount of APDC, amount of MWCNTs and the effect of extraction time were carefully evaluated. One variable at a time optimization was used to obtain the most favorable conditions for the DMSPE procedure.

\section{Effect of sample pH}

The acidity of the sample solution has a very important influence on the metal ion complexation process and therefore on extraction efficiency. The effect of the sample $\mathrm{pH}$ on recovery of
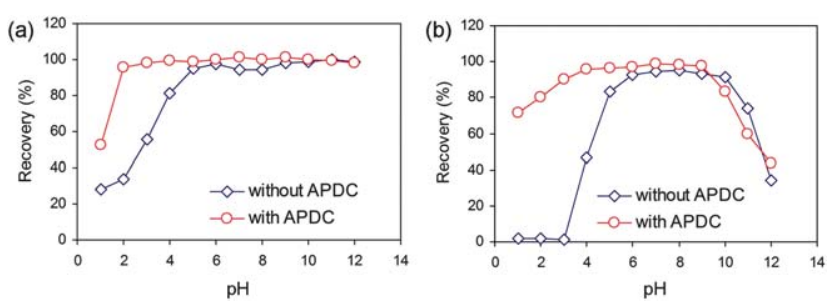

Fig. 2 The influence of $\mathrm{pH}$ on recovery of determined elements with and without application of APDC for $\mathrm{Cd}(॥)(\mathrm{a})$ and $\mathrm{Pb}(॥)(\mathrm{b})$ ions (sample volume $20 \mathrm{~mL}$, $20 \mu \mathrm{g} \mathrm{mL}^{-1}$ of APDC, $10 \mu \mathrm{g} \mathrm{mL}^{-1}$ of MWCNTs, extraction time $5 \mathrm{~min}$ ). extracted elements in the presence and in the absence of APDC was studied in the $\mathrm{pH}$ range of 1-12. As can be seen in Fig. 2, the application of APDC allows the extraction of $\mathrm{Cd}(\mathrm{II})$ and $\mathrm{Pb}$ (II) ions with high recoveries at a $\mathrm{pH}$ ranging from 2 to 12 and from 4 to 9 , respectively. When APDC is not used for the complexation of metal ions the best recoveries are observed in a narrower $\mathrm{pH}$ range - from 5 to 12 in the case of Cd(II) and from 6 to 10 in the case of $\mathrm{Pb}$ (II). Taking into account the obtained results, a sample $\mathrm{pH}$ of 7 was selected for simultaneous extraction of $\mathrm{Cd}(\mathrm{II})$ and $\mathrm{Pb}$ (II) ions from the analyzed samples. Because the application of APDC improves the recoveries, the subsequent experiments were performed using a complexing agent.

\section{Effect of the sample volume}

Another parameter that can significantly affect the global sensitivity of the methodology is the volume of the aqueous sample used for preconcentration. To evaluate this effect, two different sample volumes $(20 \mathrm{~mL}$ and $40 \mathrm{~mL})$ of an aqueous solution containing $0.4 \mu \mathrm{g}$ of $\mathrm{Cd}$ and $\mathrm{Pb}$ were analyzed in duplicate. The results obtained showed a decrease in $\mathrm{Cd}$ (II) recoveries ( $c a .86 \%$ ) when using the higher sample volume. In addition, relative standard deviations (RSDs) calculated for $\mathrm{Pb}$ and Cd measurements were also higher when using $40 \mathrm{~mL}$ of the aqueous sample to perform the analysis (8\% and $17 \%$ in comparison with $6 \%$ and $10.5 \%$ for $\mathrm{Cd}(\mathrm{II})$ and $\mathrm{Pb}(\mathrm{II})$, respectively). Therefore, a sample volume of $20 \mathrm{~mL}$ of the aqueous sample was selected for further experiments.

\section{Effect of the amount of APDC}

APDC allows the formation of hydrophobic complexes that can be absorbed on the MWCNT surface through van der Waals forces and hydrophobic interactions. ${ }^{16}$ Therefore, the influence of the concentration of the complexing agent on the recovery of determined elements was investigated (see Fig. 3a). The results obtained showed that the APDC concentration has no impact on the efficiency of the developed analytical procedure within the studied range $\left(5-30 \mu \mathrm{g} \mathrm{mL}^{-1}\right)$. Finally, an APDC concentration of $20 \mu \mathrm{g} \mathrm{mL}^{-1}$ was selected for subsequent experiments.

\section{Effect of the amount of MWCNTs}

The amount of MWCNTs used for preconcentration can have a significant influence on the extraction of metals from the aqueous solution but also on the later TXRF analysis. As stated in the Introduction section, to perform the analysis under total reflection conditions, analyzed samples must be deposited as thin layers on a reflective carrier. Therefore, the thickness of the deposited samples, which is related to the amount of MWCNTs used, can have influence on the final determination of our analytes. Fig. 3b depicts the influence of MWCNT amount (within the range of 2-20 $\mu \mathrm{g} \mathrm{mL}^{-1}$ ) on the recovery values for $\mathrm{Pb}$ (II) and $\mathrm{Cd}$ (II). As is shown, low $\mathrm{Cd}$ (II) and $\mathrm{Pb}$ (II) recoveries (ca. $50 \%$ ) were obtained when using low MWCNT concentrations (2

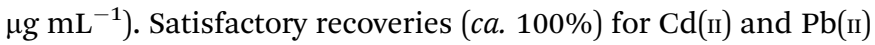
ions were achieved for concentrations of MWCNTs ranging from 5 to $10 \mu \mathrm{g} \mathrm{L}^{-1}$. With further increase of the absorbent amount, recovery values decreased considerably for both 

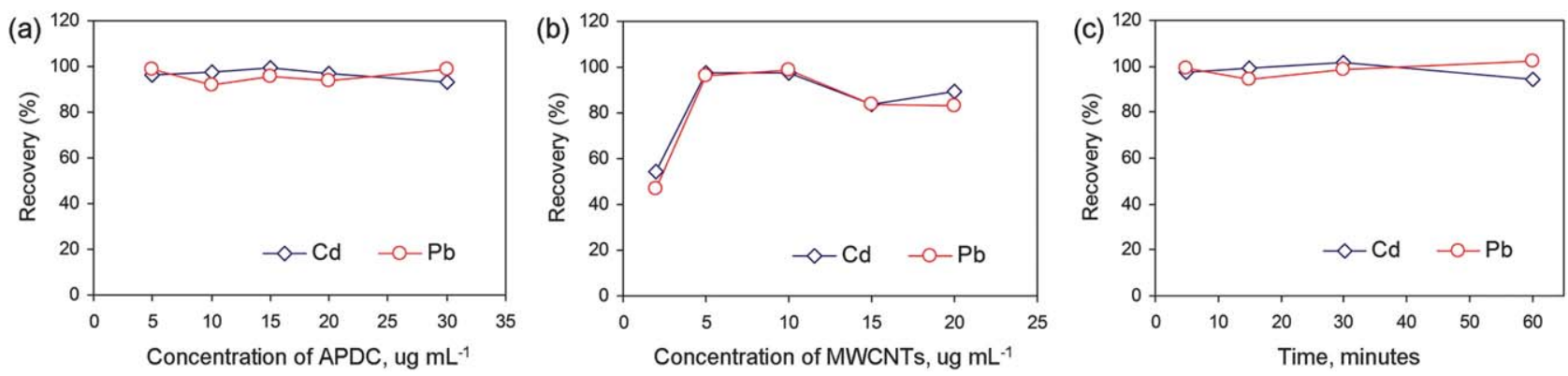

Fig. 3 The influence of some parameters on the determination of $\mathrm{Cd}(\|)$ and $\mathrm{Pb}(\|)$ ions by the DMSPE + TXRF procedure: (a) APDC concentration ( $\mathrm{pH}=7$, sample volume $20 \mathrm{~mL}, 10 \mu \mathrm{g} \mathrm{mL}^{-1}$ of MWCNTs, extraction time $5 \mathrm{~min}$ ), (b) MWCNT concentration ( $\mathrm{pH}=7$, sample volume $20 \mathrm{~mL}^{2} 20 \mu \mathrm{g} \mathrm{mL}{ }^{-1}$ of APDC, extraction time $5 \mathrm{~min}$ ) and (c) extraction time ( $\mathrm{pH}=7$, sample volume $20 \mathrm{~mL}, 20 \mu \mathrm{g} \mathrm{mL}$ of APDC, $10 \mu \mathrm{g} \mathrm{mL}^{-1}$ of MWCNTs).

determined elements. This fact demonstrated that probably when working with such a high amount of MWCNTs the thin layer is broken and thus the analysis cannot be performed under total-reflection conditions. In view of the obtained results, a MWCNT concentration of $10 \mu \mathrm{g} \mathrm{mL} \mathrm{mL}^{-1}$ was established for further experiments.

\section{Effect of extraction time}

In DMSPE it is also of significance to establish an appropriate contact time (period between the addition of the sorbent to the analyzed sample and the centrifugation step) to obtain high analyte extraction rates. In Fig. 3c, the effect of extraction time on $\mathrm{Cd}(\mathrm{II})$ and $\mathrm{Pb}$ (II) recoveries is shown. As can be seen, the extraction time does not affect the determination of analytes in the studied working range (from 5 to $60 \mathrm{~min}$ ). This fact can be related to the large contact area between dispersed MWCNTs and the aqueous sample that provides a fast achievement of the equilibrium state. The adsorption occurs immediately, and the extraction time has no influence on the adsorption of the metal-APDC complexes onto the surface of MWCNTs. ${ }^{14}$ In order to reduce the analysis time of the developed methodology, a stirring time of 5 min was chosen for subsequent experiments.

\section{Selection of analytical conditions for TXRF measurements}

Parameters affecting the sample deposition step (sample deposition volume and drying mode) as well as operating conditions for TXRF measurements were evaluated to obtain the best sensitivity for $\mathrm{Cd}$ and $\mathrm{Pb}$ determination.

\section{Influence of sample deposition volume}

The aim of the sample preparation process in TXRF is to obtain the target sample as a thin layer $(<100 \mu \mathrm{m})$ on a carrier with high reflectivity sample support. Therefore, the choice of adequate sample deposition volume is of crucial importance in order to obtain a thin layer and to ensure the conditions of total reflection. Moreover the diameter of the sample spot on the sample carrier has to be within the beam size to ensure the complete exposition of the drop to the X-ray beam. For that, only a few microliters of solution are usually employed. In Fig. 4a, the effect of sample deposition volume on $\mathrm{Cd}$ and $\mathrm{Pb}$ relative intensities $\left(I_{\mathrm{Cd}} / I_{\mathrm{Y}}\right.$ and $\left.I_{\mathrm{Pb}} / I_{\mathrm{Y}}\right)$ obtained for the analysis of a preconcentrated standard solution containing $20 \mathrm{ng} \mathrm{mL}^{-1}$ of both metals is shown. As can be seen, no statistically significant differences on relative analyte responses were obtained when depositing 5 or $10 \mu \mathrm{L}$ of the sample on the reflector. A slight decrease of $\mathrm{Cd}$ and $\mathrm{Pb}$ relative intensities was observed when using higher sample deposition volumes. In view of the obtained results, a volume of $10 \mu \mathrm{L}$ was established for further experiments.

\section{Influence of sample drying}

After the deposition procedure on the reflector, the microdroplet must be properly dried to perform the TXRF analysis. Therefore, another parameter that can significantly affect the final analytical TXRF results is the drying mode used. For that, different drying modes were tested in order to ensure the achievement of a centered-thin film on the reflector when
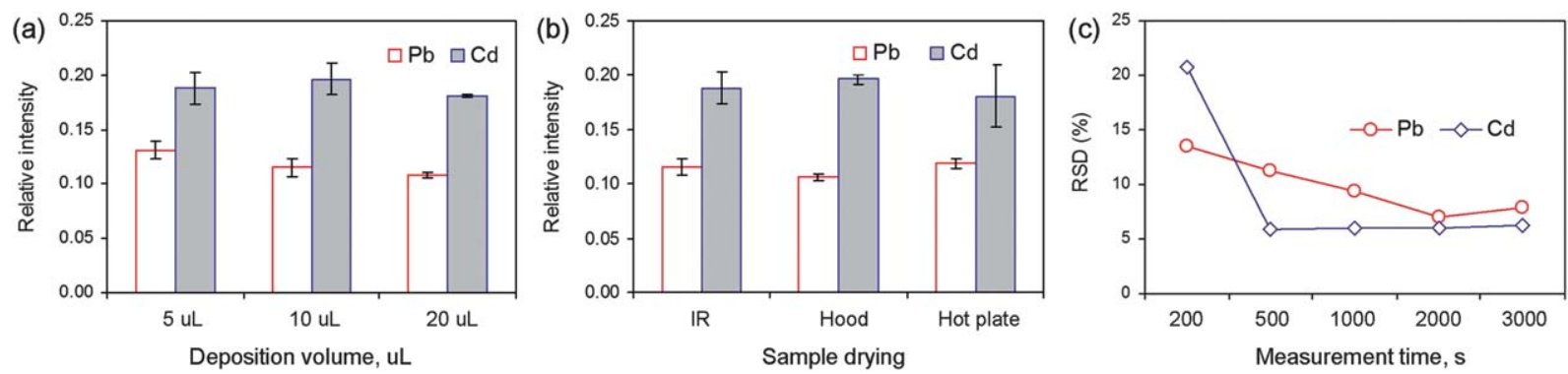

Fig. 4 The influence of: (a) sample deposition volume, (b) sample drying mode and (c) measurement time on the relative intensity of $\mathrm{Cd}(॥)$ and $\mathrm{Pb}(॥)$ ions by the $\mathrm{DMSPE}$ + TXRF procedure. 
analyzing a preconcentrated standard solution containing $20 \mathrm{ng}$ $\mathrm{mL}^{-1}$ of $\mathrm{Cd}$ and $\mathrm{Pb}$ : (i) drying under a laminar flow hood (room temperature), (ii) drying under an IR-lamp and (iii) drying on a hot plate set at $\sim 80{ }^{\circ} \mathrm{C}$. Results showed that for this type of deposited sample (suspension of loaded MWCNTs) the drying mode is not a critical parameter and no statistically significant differences were found for the different drying modes tested (see Fig. 4b). Finally, samples were dried under an IR-lamp for practical reasons.

\section{Operating conditions for TXRF measurements}

Operating conditions for TXRF measurements were also evaluated to obtain the best instrumental sensitivity for $\mathrm{Cd}$ and $\mathrm{Pb}$ determination. The rate of $\mathrm{kV}$ and $\mathrm{mA}$ of the X-ray tube was selected to work under conditions of maximum efficiency of excitation $(50 \mathrm{kV}, 1 \mathrm{~mA}$, max. power $50 \mathrm{~W})$. The measurement time was selected with respect to the lowest relative standard deviation (RSD) obtainable as detailed in Fig. 4c. Each experimental point represents the RSD value calculated from the analysis of five replicates of a deposited preconcentrated sample containing $20 \mathrm{ng} \mathrm{mL}^{-1}$ of $\mathrm{Cd}$ and $\mathrm{Pb}$. As expected, the higher the integration time the lower the standard deviation until a constant value was reached (RSD $\sim 5$ to $10 \%$ ). From these results, a measurement time of $2000 \mathrm{~s}$ was fixed.

\section{Analytical figures of merit of the DMSPE + TXRF system}

First of all, a study was conducted to study the benefits of the proposed preconcentration methodology for $\mathrm{Cd}$ and $\mathrm{Pb}$ determination by TXRF. In Fig. 5, the comparison between TXRF spectra obtained for the direct analysis of an aqueous standard solution containing $20 \mathrm{ng} \mathrm{mL} L^{-1}$ of $\mathrm{Cd}$ and $\mathrm{Pb}$ and after the DMSPE + TXRF procedure is shown. It is clear that the proposed DMSPE preconcentration method offers obvious benefits in terms of sensitivity compared to analysis of aqueous samples without preconcentration. This fact is particularly interesting when using portable TXRF systems that offer extreme simplicity of operation in a low-cost compact design (no cooling media or gas consumption are required for operation) but they also present limited sensitivity compared with high-scale

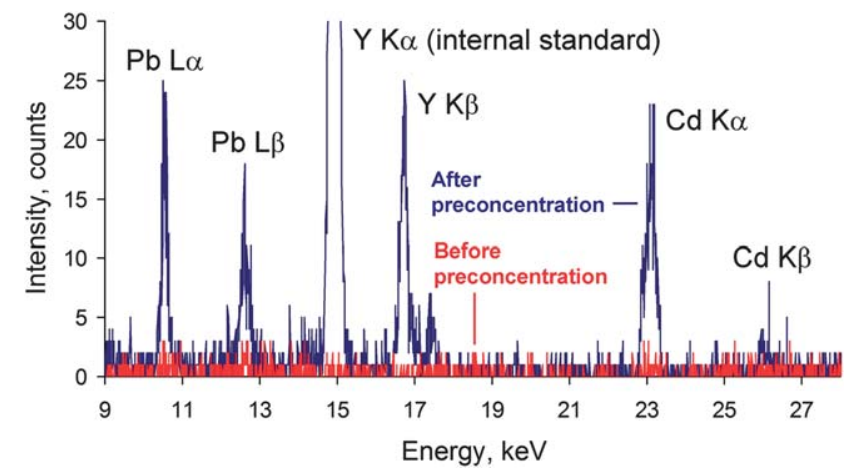

Fig. 5 Comparison between TXRF spectra obtained for the direct analysis of an aqueous standard solution containing $20 \mathrm{ng} \mathrm{mL}^{-1}$ (red line) and after the DMSPE + TXRF procedure (blue line).
Table 2 Calibration curve parameters and DLs for determination of $\mathrm{Cd}(॥)$ and $\mathrm{Pb}(I)$ ions by combination of DMSPE and portable TXRF spectrometry. The concentration of $\mathrm{Cd}(॥)$ and $\mathrm{Pb}(\|)$ are in $\mathrm{ng} \mathrm{mL}^{-1}$

\begin{tabular}{llll}
\hline Analyte & Equation & $R$ & $\mathrm{DL}, \mathrm{ng} \mathrm{mL}^{-1}$ \\
\hline $\mathrm{Cd}$ & $I_{\mathrm{Cd}} / I_{\mathrm{Y}}=(0.00925 \pm 0.00023) \times$ & 0.9988 & 1.0 \\
& $C_{\mathrm{Cd}}-(0.007 \pm 0.011)$ & & \\
$\mathrm{Pb}$ & $I_{\mathrm{Pb}} / I_{\mathrm{Y}}=(0.00434 \pm 0.0001) \times$ & 0.9980 & 2.1 \\
& $C_{\mathrm{Pb}}+(0.013 \pm 0.006)$ & & \\
\hline
\end{tabular}

instrumentation. If the parameters for TXRF spectra shown in Fig. 5 (net intensity and background) are used to estimate the detection limits (DLs) according to the $3 \sigma$ approach, ${ }^{20}$ values of approximately $1.0 \mathrm{ng} \mathrm{mL}^{-1}$ for $\mathrm{Cd}(\mathrm{II})$ and $2.1 \mathrm{ng} \mathrm{mL}^{-1}$ for $\mathrm{Pb}(\mathrm{II})$ are obtained. These values are below the maximum contaminant levels for $\mathrm{Cd}(\mathrm{II})\left(5 \mathrm{ng} \mathrm{mL} \mathrm{m}^{-1}\right.$ (ref. 22)) and $\mathrm{Pb}$ (II) (15 $\mathrm{ng} \mathrm{mL}^{-1}$ (ref. 23)), that might be found in drinking water according to United States Environmental Protection Agency (EPA). Moreover, calculated DLs are below the Polish regulations for bottled water $\left(3 \mathrm{ng} \mathrm{mL}^{-1}\right.$ and $10 \mathrm{ng} \mathrm{mL}^{-1}$ for $\mathrm{Cd}(\mathrm{II})$ and $\mathrm{Pb}(\mathrm{II})$, respectively). ${ }^{24}$

The linearity of the proposed analytical procedure was examined for the concentration of analytes in the range of 5$50.0 \mathrm{ng} \mathrm{mL}{ }^{-1}$. To reduce inaccuracies due to sample deposition on the sample carrier calibration using internal standardization was used. The obtained results show that the proposed methodology is linear for the entire range of examined concentrations. Calibration parameters (slope, intercept, and correlation coefficient) are listed in detail in Table 2.

The total uncertainty of the developed methodology (DMSPE + TXRF) consists of the errors associated with the extraction step, errors linked to the deposition of the sample onto the carrier and errors related to instrument and counting statistics from the TXRF system. In order to evaluate the extent of each one of these errors, five independent solutions containing $20 \mathrm{ng}$ $\mathrm{mL}^{-1}$ of $\mathrm{Cd}$ and $\mathrm{Pb}$ were preconcentrated and measured under optimized conditions (total uncertainty). Besides, one of the preconcentrated samples was analyzed by the deposition on five different carriers (deposition of the sample on the carrier + instrumental errors) and one of the carriers was analyzed five times (instrumental errors). In all cases, the RSDs associated were calculated and values are presented in Table 3. As is shown, the combination of TXRF and DMSPE is characterized by satisfactory total uncertainty precision (RSD $\sim 5$ to $10 \%$ ). It is also interesting to remark that the uncertainty associated with

Table 3 The relative standard deviations (RSDs) describing the precision of the extraction step, pipetting the sample onto the carrier, the measurement of analytes and the total uncertainty of the developed methodology

\section{RSD, \%}

\begin{tabular}{llllc} 
Analyte & Extraction & Pipetting & Measurement & Total uncertainty \\
\hline $\mathrm{Cd}$ & 4.2 & 3.4 & 2.6 & 6.0 \\
$\mathrm{~Pb}$ & 9.6 & 2.6 & 3.2 & 10.5
\end{tabular}


Table 4 Analytical results (mean $\pm S D, n=3$ ) for cadmium and lead in water samples

\begin{tabular}{|c|c|c|c|c|}
\hline Element & Sample & $\begin{array}{l}\text { Added, } \\
\text { ng } \mathrm{mL}^{-1}\end{array}$ & $\begin{array}{l}\text { Found, } \\
\text { ng mL }\end{array}$ & $\begin{array}{l}\text { Recovery } \\
(\%)\end{array}$ \\
\hline \multirow[t]{9}{*}{$\mathrm{Cd}$} & \multirow[t]{3}{*}{ Sea water } & 0 & $5 \pm 1.2$ & \\
\hline & & 20 & $26 \pm 3.6$ & 105 \\
\hline & & 50 & $57 \pm 3.6$ & 104 \\
\hline & \multirow[t]{3}{*}{ River water } & 0 & $3.9 \pm 0.5$ & \\
\hline & & 20 & $27 \pm 3.0$ & 116 \\
\hline & & 50 & $58.3 \pm 0.9$ & 109 \\
\hline & \multirow[t]{3}{*}{ Waste water } & 0 & $3.4 \pm 0.3$ & \\
\hline & & 20 & $24 \pm 4.5$ & 103 \\
\hline & & 50 & $56 \pm 2.3$ & 105 \\
\hline \multirow[t]{9}{*}{$\mathrm{Pb}$} & \multirow[t]{3}{*}{ Sea water } & 0 & $12 \pm 1.8$ & \\
\hline & & 20 & $32.2 \pm 0.5$ & 101 \\
\hline & & 50 & $67 \pm 3.7$ & 110 \\
\hline & \multirow[t]{3}{*}{ River water } & 0 & $7 \pm 1.6$ & \\
\hline & & 20 & $30 \pm 2.3$ & 115 \\
\hline & & 50 & $58 \pm 4.4$ & 102 \\
\hline & \multirow[t]{3}{*}{ Waste water } & 0 & $7 \pm 1.5$ & \\
\hline & & 20 & $28 \pm 2.5$ & 105 \\
\hline & & 50 & $53.5 \pm 0.5$ & 93 \\
\hline
\end{tabular}

the extraction step is the greatest contribution to the total uncertainty of the DMSPE-TXRF system.

\section{Analytical application}

The proposed method for simultaneous determination of $\mathrm{Cd}$ (II) and $\mathrm{Pb}(\mathrm{II})$ by DMSPE-TXRF was applied to the analysis of different types of water samples including sea water, river water and waste water. The reliability of the developed procedure was examined by the analysis of water samples spiked with 20 and $50 \mathrm{ng} \mathrm{mL}{ }^{-1}$ of $\mathrm{Cd}(\mathrm{II})$ and $\mathrm{Pb}(\mathrm{II})$. According to the results presented in Table 4, the recoveries for spiked water samples averaged $106 \%$ and $104 \%$ for $\mathrm{Cd}(\mathrm{II})$ and $\mathrm{Pb}(\mathrm{II})$, respectively. The highest RSDs were obtained for samples which did not contain the addition of the standard solution due to the proximity of the measured concentrations to the DLs. The results summarized in Table 4 show that the developed combination of DMSPE and TXRF is suitable for the simultaneous determination of $\mathrm{Cd}(\mathrm{II})$ and $\mathrm{Pb}$ (II) ions in real water samples, including sea water.

\section{Conclusions}

The results of the present investigation show that DMSPE combined with TXRF spectrometry is a powerful methodology for the determination of low levels of $\mathrm{Cd}(\mathrm{II})$ and $\mathrm{Pb}$ (II) ions in water samples. Application of MWCNTs in DMSPE provides a large contact area between the sorbent and analytes of interest, so the equilibrium state is achieved immediately and the extraction process is almost time independent. The use of TXRF as the detection system eliminates the need for an elution step after the adsorption process of the analytes on the MWCNTs, simplifying the procedure and reducing the total analysis time. Additional advantages of the TXRF method proposed are the possibility to detect simultaneously $\mathrm{Cd}$ and
$\mathrm{Pb}$ ions in the sample and the low operating costs since the portable TXRF system used does not require cooling media and gas for operation. The achieved DLs are below the maximum $\mathrm{Cd}$ and $\mathrm{Pb}$ contents permissible in drinking waters according to EPA and Polish regulations for bottled water and the accuracy and precision of the obtained results are adequate for the intended purpose. The developed analytical methodology has been successfully applied for the determination of $\mathrm{Cd}$ and $\mathrm{Pb}$ in the low $\mathrm{ng} \mathrm{\textrm {mL } ^ { - 1 }}$ range in different types of water samples.

\section{Acknowledgements}

This work was supported by the Spanish National Research Program (Project ref. CGL2010-22168-C03-01) and the Bilateral Agreement (Lifelong Learning Program/Erasmus) for the Academic year 2012-2013 between the University of Silesia (Poland) and the University of Girona (Spain). Karina Kocot is grateful for the financial support of the UPGOW project, cofinanced by the European Union within the European Social Fund.

\section{Notes and references}

1 S. Armenta, S. Garrigues and M. de la Guardia, TrAC, Trends Anal. Chem., 2008, 27, 497.

2 F. Pena-Pereira, I. Lavilla and C. Bendicho, TrAC, Trends Anal. Chem., 2010, 29, 617.

3 S. A. Ahmed, J. Hazard. Mater., 2008, 156, 521.

$4 \mathrm{~W}$. Ngeontane, W. Aeungmaitrepirom and T. Tuntulani, Talanta, 2007, 71, 1075.

5 P. R. Aranda, S. Moyano, L. D. Martinez and I. E. de Vito, Anal. Bioanal. Chem., 2010, 398, 1043.

6 M. Cruz-Vera, R. Lucena, S. Cárdenas and M. Valcárcel, Anal. Methods, 2011, 3, 1719.

7 J. M. Jiménez-Soto, S. Cárdenas and M. Valcárcel, Anal. Chim. Acta, 2012, 714, 76.

$8 \mathrm{~J}$. M. Jiménez-Soto, S. Cárdenas and M. Valcárcel, J. Chromatogr., A, 2012, 1245, 17.

9 S.-C. Fu, S. H. Tzing, H.-C. Chen, Y.-C. Wang and W.-H. Ding, Anal. Bioanal. Chem., 2012, 402, 2209.

10 F. Galán-Cano, R. Lucena, S. Cárdenas and M. Valcárcel, Anal. Methods, 2011, 3, 991.

11 M. C. Alcudia-León, R. Lucena, S. Cárdenas and M. Valcárcel, Anal. Chem., 2009, 81, 1184.

12 B. Zawisza, R. Skorek, G. Stankiewicz and R. Sitko, Talanta, 2012, 99, 918.

13 R. Skorek, E. Turek, B. Zawisza, E. Margui, I. Queralt, M. Stempin, P. Kucharski and R. Sitko, J. Anal. At. Spectrom., 2012, 27, 1688.

14 R. Skorek, B. Zawisza, E. Margui, I. Queralt and R. Sitko, Appl. Spectrosc., 2013, 67, 204.

15 G. Lasarte-Aragonés, R. Lucena, S. Crdenas and M. Valcrcel, Bioanalysis, 2011, 3, 2533.

16 R. Sitko, B. Zawisza and E. Malicka, TrAC, Trends Anal. Chem., 2012, 37, 22. 
17 H. Abdolmohammad-Zadeh and Z. Talleb, Microchim. Acta, 2012, 179, 25.

18 K. M. Giannoulis, G. Z. Tsogas, D. L. Giokas and A. G. Vlessidis, Talanta, 2012, 99, 62.

19 E. Marguí, J. C. Tapias, A. Casas, M. Hidalgo and I. Queralt, Chemosphere, 2010, 80, 263.

20 R. Klockenkämper, Total Reflection X-ray Fluorescence Analysis, ed. J. D. Winefordner, John Wiley \& Sons, New York, 1997.
21 S2 PICOFOX ${ }^{\mathrm{TM}}$, User Manual, Bruker advanced X-ray solutions, Bruker AXS Microanalysis GmH, Berlin (Germany), 2007.

22 http://water.epa.gov/drink/contaminants/basicinformation/ cadmium.cfm, retreived 2012-10-08.

23 http://water.epa.gov/drink/contaminants/basicinformation/ lead.cfm, retrieved 2012-10-08.

24 The Health Minister's Regulation, Dz.U.04.120.1256, The Official Journal of Law 04.120.1256. 